\title{
Crosslinked network development in compatibilized alkyd/acrylic hybrid latex films for the creation of hard coatings
}

Tao Wang†§ll, Carolina de las Heras Alarcón†§, Monika Goikoetxeał, Itxaso Beristain‡, Maria Paulisł, Maria J. Barandiaran‡, José M. Asuał, and Joseph L. Keddie†*

†Department of Physics and Surrey Materials Institute, University of Surrey, Guildford GU2 7XH, UK

‡Institute of Polymer Materials (POLYMAT), Grupo de Ingeniería Química, University of the Basque Country, Centro Joxe Mari Korta, Avenida Tolosa 72, 20018 Donostia- San Sebastián, Spain

§These authors contributed equally to this work. ICurrent address: Department of Physics and Astronomy, University of Sheffield, Sheffield, S3 7RH, UK.

*Corresponding author. E-mail: j.keddie@ surrey.ac.uk Tel.: +44-1483-686803 Fax: $+44-1483-686781$ 
Abstract: Hybrids made from an alkyd resin and an acrylic copolymer can potentially combine the desired properties of each component. Alkyd/acrylic hybrid latex particles were synthesized via miniemulsion polymerization and used to create films at room temperature. Comparisons of the alkyd auto-oxidative crosslinking rates and the associated network development are made between two alkyd resins (with differing levels of hydrophilicity as measured by their acid numbers). The effects of increasing the compatibilization between the alkyd and the acrylic phase via functionalization with glycidyl methacrylate (GMA) are investigated. Magnetic resonance profiling and micro-indentation measurements reveal that film hardening occurs much faster in a GMA-functionalized alkyd hybrid than in the standard hybrid. The film's hardness increases by a factor of four over a five-day period. The rate of crosslinking is significantly slower in non-functionalized alkyd hybrid films and when the more hydrophilic alkyd resin is used. Tensile deformation of the hybrid latex films reveals the effects of GMA functionalization and drier concentration in creating a denser crosslinked network. Modeling of the tensile deformation behavior of the hybrid films used a combination of the Upper Convected Maxwell model (to describe the viscoelastic component) and the Gent model (to describe the elastic component). The modeling provides a correlation between the crosslinked network formation and the resulting mechanical properties.

Keywords: Alkyd-acrylic hybrid, Glycidyl methacrylate, Magnetic resonance profiling, Crosslinking, Hardness, Mechanical modeling. 


\section{Introduction}

Alkyd resins have been widely used in coating applications. They can be dissolved in an organic solvent and cast from the solution to create glossy coatings that penetrate well into porous substrates. Although alkyd resins typically have a low molecular weight and a glass transition temperature far below ambient conditions, they can undergo auto-oxidative crosslinking reactions that lead to a large increase in hardness over time. ${ }^{1}$ Two drawbacks of alkyds coatings are their tendency to yellow and their slow rate of crosslinking, which is associated with a long time before they are hardened. To alleviate the second problem, metal ion catalysts, known as driers, are incorporated in formulations to increase the rate of alkyd crosslinking., ${ }^{2,3,4,5,6}$ Alkyds can be emulsified in water and used to create a waterborne coating, which is more environmentally-friendly in comparison to solvent-cast materials. In this case, the viscosity rise of the coating, which is caused by particle packing at the gel point during the drying process, is much faster than what is found for solvent-cast alkyds. Hence, there is a relatively narrow window of time that a waterborne coating can be "re-worked", which is referred to as having a short "open time" in the coatings literature. $^{7}$

Acrylic latexes, synthesized through emulsion polymerization, are likewise commonly used to create clear, waterborne coatings. In comparison to alkyd emulsions, acrylic latexes offer coatings with longer open times, good film formation, chemical resistance, and consistent clarity (non-yellowing). However, without the addition of plasticizers, the acrylic's glass transition temperature must be less than the 
processing temperature in order to achieve film formation. ${ }^{8}$ Consequently, there is a limit to the hardness that can be achieved from plasticizer-free, acrylic latex films at room temperature.

Over the past couple of decades, there have been numerous examples in which waterborne hybrid polymers have been effective in combining the desirable properties of their constituents. ${ }^{9}$ One system of particular interest has been hybrid latex made from alkyd resins and acrylic copolymers. ${ }^{10,11,12,13,14,15,16,17,18,19}$ Whereas successful applications as a protective or architectural coating require that the alkyd component in the hybrid crosslinks and hence hardens, most of the published work has focused on the synthesis (mainly by miniemulsion polymerization) of alkyd/acrylic hybrid latexes $^{10,11,12,13,14,16,17,18}$ and the resulting particle and film morphology. ${ }^{15,17,20,21} \mathrm{~A}$ hybrid film that does not harden after film casting at ambient temperatures (typically $20^{\circ} \mathrm{C}$ ) would be of little practical value as a household architectural coating. It has been found, however, that a hybrid alkyd/acrylic latex has a greater film hardness than the corresponding blend of components. ${ }^{17}$ The hardness of an alkyd/acrylic hybrid film has also been shown to be increased when a latent oxidative functional monomer is used in the synthesis. ${ }^{16}$ Furthermore, the dynamic mechanical properties of an alkyd/acrylic hybrid has been correlated with the material morphology, but the time-dependence of properties was not studied. ${ }^{15}$

A potential problem during the synthesis of alkyd/acrylic hybrid latex is that, during miniemulsion polymerization, the radicals in the miniemulsion media can react with the carbon-carbon double bonds of the alkyd. The number of the unsaturated 
groups of the alkyd resin component will then be reduced, and consequently the auto-oxidation during the film formation process and associated network formation and film hardening will be hindered. Goikoetxea et al. have recently developed a new strategy for synthesizing alkyd/acrylic hybrids, which relies on the use of methacrylate-functionalized alkyd resins in miniemulsion polymerization. ${ }^{22}$ These functionalized alkyd resins are prepared by reaction of the alkyd resin and glycidyl methacrylate (GMA) prior to the miniemulsion polymerization to prepare waterborne alkyd/acrylic hybrids. By enabling the acrylic to bond to the alkyd chains via the GMA moiety, the strategy improves the compatibility between the alkyd and acrylic components without reducing the number of alkyd unsaturated double bonds that are involved in the auto-oxidation process. ${ }^{22}$ The present work investigates how the compatibilization of the alkyd and acrylic influences the molecular network development and mechanical properties of films.

Whereas the previous work, outlined above, did not consider the evolution of the crosslinked network over time, here we report an analysis of the crosslinking in alkyd/acrylic hybrid latex films spanning from the moment of film deposition to 60 days later. Nuclear magnetic resonance (NMR) profiling is employed as a non-invasive probe of the density of mobile ${ }^{1} \mathrm{H}$ as a function of position in the drying hybrid films. The NMR signal decreases as water evaporates during the first stage of the film formation, because the highly-mobile ${ }^{1} \mathrm{H}$ in water is lost. $^{2}$ There is a further decrease in the signal as the degree of crosslinking increases, because the mobility of the resin molecules decreases. ${ }^{2-6}$ Previously, NMR profiling was used to study 
crosslinking in latex ${ }^{23}$ and in alkyd emulsion ${ }^{2,24}$ films and shown to be an ideal, non-invasive technique for such systems.

In this work, the mechanical evolution, which is associated with the crosslinking development in the hybrid film, was determined by micro-indentation of supported films and stress-strain measurements of free-standing films. Modeling of the large-strain deformation of alkyd-acrylic latex films, by a combination of the Upper Convected Maxwell ${ }^{25}$ model and the Gent model ${ }^{26}$, was also performed to understand the development of the crosslinked network and how it is influenced by the compatibilization between the alkyd and acrylic phases.

\section{Materials and Methods}

\subsection{Materials}

Technical grade monomers, methyl methacrylate (MMA, Quimidroga), butyl acrylate (BA, Quimidroga), acrylic acid (AA, Aldrich), stearyl acrylate (SA, Aldrich) and glycidyl methacrylate (GMA, Aldrich), were used without purification. Stearyl acrylate plays the role of both monomer and costabilizer (to avoid the Oswald ripening effect). Two kinds of alkyd resins were used: SETAL 293 (acid value of 11 $\mathrm{mg} \mathrm{KOH} / \mathrm{g}$; weight average molecular weight, $M_{\mathrm{w}}=7570 \mathrm{~g} / \mathrm{mol}$ and polydispersity, $M_{\mathrm{w}} / M_{\mathrm{n}}=2.48$ ) and the more hydrophilic SETAL 1630WP-292 (acid value of $21.5 \mathrm{mg}$ $\mathrm{KOH} / \mathrm{g} ; M_{\mathrm{w}}=6460 \mathrm{~g} / \mathrm{mol}$ and polydispersity, $M_{\mathrm{w}} / M_{\mathrm{n}}=2.31$ ), both supplied by Nuplex Resins. The iodine value, which is proportional to the content of double bonds, is similar for both resins $(110-120 \mathrm{~g} / 100 \mathrm{~g})$. Hereafter, HB will be used to refer to the 
more hydrophobic alkyd resin (SETAL 293), as gauged by its acid value, and HL will refer to the more hydrophilic resin (SETAL 1630WP-292). Dowfax 2A1 (alkyldiphenyl oxide disulfonate, Dow Chemicals) was used as surfactant. A water soluble initiator, (potassium persulfate, KPS, Panreac) and an organic soluble initiator, (2,2 -azobis(2-methylbutyronitrile), V59, Wako Chemicals) were used as thermal initiators. Ammonium persulfate (APS, Panreac) and sodium metabisulfite (SMB, Fluka) were used as redox initiators. Sodium bicarbonate $\left(\mathrm{NaHCO}_{3}\right.$ supplied by Riedel-de Haën) was added to reduce the Debye screening length and hence to reduce the miniemulsion viscosity. GPC grade tetrahydrofuran (THF, Scharlau) was used as received. Distilled water was used throughout the work. The weight ratio of the alkyd:acrylic components in the hybrid latexes was fixed at 50:50. The mass ratio of the acrylic monomers MMA:BA:SA:AA was 47.6:47.6:3.8:1. Dowfax 2A1 was used at an amount of $6 \mathrm{wt} . \%$, expressed on the organic phase.

\subsection{GMA Functionalization}

Both alkyd resins were functionalized by reacting with GMA. An equimolar mixture of alkyd resin and GMA, as well as a hydroquinone aqueous solution, which is issued to avoid the GMA homopolymerization, were charged to a reactor. Details are given elsewhere. ${ }^{22}$ The epoxide moiety of the GMA reacts with either the $-\mathrm{COOH}$ or the $-\mathrm{OH}$ groups of the alkyd resin, producing the methacrylate-functionalized resin. After the functionalization with GMA, the acid value of both resins decreased, and approximately $65 \%$ and $35 \%$ of the $-\mathrm{COOH}$ groups of the $\mathrm{HB}$ and $\mathrm{HL}$ resins, respectively, reacted with GMA. It was found previously, that the double bonds of the 
alkyd resin did not suffer any modification during functionalization. ${ }^{22}$

\subsection{Miniemulsion polymerization of alkyd-acrylic hybrid latexes}

The alkyd/acrylic hybrid latexes were synthesized in batch by miniemulsion polymerization at $70{ }^{\circ} \mathrm{C}$ (the non-functionalized alkyd system) or $90{ }^{\circ} \mathrm{C}$ (the GMA-functionalized system), following the method reported in the literature. ${ }^{18,22}$, Polymerizations were carried out in a $1 \mathrm{~L}$ glass reactor equipped with a reflux condenser, stirrer, sampling device, nitrogen inlet, and two feed inlet tubes. When the redox initiator system was used, its components were fed separately over 4 hours. Then the system was allowed to react in batch for one more hour. The physical properties of as-synthesized alkyd/acrylic hybrid latexes are summarized in Table 1. The GMA prefix in the name of the alkyd refers to the alkyds that were functionalized.

\subsection{Alkyd Emulsification and Blends}

For comparison purposes, some blends of alkyd emulsions and acrylic latexes were prepared. First, each of the two alkyd resins (HB and HL) was emulsified. The resin and an aqueous solution of Dowfax 2A1 (1.8 wt.\%) were mixed together and stirred magnetically for $20 \mathrm{~min}$. The resulting coarse emulsion was sonified (Branson 450) for 15 min. (power 9 and $80 \%$ duty cycle). The emulsion was treated (6 cycles) with a Niro-Soavi high-pressure homogenizer with pressures of 410 and 41 bar in the first and second stage valves, respectively. The average alkyd droplet size for the HB resin was $900 \mathrm{~nm}$ and $640 \mathrm{~nm}$ for the HL resin. Blends of the resin emulsions with a $50 \%$ solids content blank acrylic latex (MMA:BA:SA:AA mass ratios of 47.6:47.6:3.8:1) 
in a $1: 1$ ratio by weight were then prepared.

\subsection{Latex Characterization}

Droplet and particle sizes were determined by dynamic light scattering, using a Malvern Nanosizer. The characterization of the alkyd/acrylic hybrid latexes included also the determination of the fraction of alkyd resin grafted to the acrylic polymer (RDG), the fraction of consumed double bonds of the alkyd resin (RDB), and the gel content.

The sol fraction of the latex was separated from the gel fraction using Soxhlet extraction with THF. The non-soluble part was considered to constitute the gel fraction. The sol fraction was directly injected into SEC equipment (LC-20AD Shimadzu pump, Waters Styragel HQ2, HQ4, HQ6 columns and two on-line detectors: differential refractometer (DR) and UV (Waters)) to determine RDG. The method relies on the fact that the acrylic polymer is not detected by the UV sensor at a wavelength of $263 \mathrm{~nm}$, as is reported elsewhere. ${ }^{27}$

The RDB was determined by iodine titration based on the Wijs method. ${ }^{28}$ As can be seen in Table 1, the alkyd/acrylic hybrid waterborne dispersions made with the functionalized resin presented an important increase in the grafting of the resin to the acrylic chain (RDG) whereas the double bonds of the resin available for curing (RDB) were not much affected. Only the GMA-HB hybrid has a significant gel content.

Table 1. Chemical components and characteristics of the alkyd-acrylic hybrid latexes 


\begin{tabular}{|c|c|c|c|c|c|c|c|}
\hline $\begin{array}{c}\text { Hybrid Code } \\
\text { Name }\end{array}$ & $\begin{array}{c}\text { Alkyd } \\
\text { Acid value } \\
(\mathrm{mg} \mathrm{KOH/g} \\
\text { resin) }\end{array}$ & $\begin{array}{c}\text { Initiator } \\
(\mathrm{wt} \%)\end{array}$ & $\begin{array}{c}\text { Average } \\
\text { particle size } \\
(\mathrm{nm})\end{array}$ & $\begin{array}{c}\text { Solids content } \\
(\mathrm{wt} . \%)\end{array}$ & $\begin{array}{c}\text { Gel } \\
\text { content } \\
(\mathrm{wt} . \%)\end{array}$ & $\begin{array}{c}\text { RDG } \\
(\%)\end{array}$ & $\begin{array}{c}\text { RDB } \\
(\%)\end{array}$ \\
\hline HB & 11 & KPS (1.6) & 129 & 43 & 0 & 39 & 8 \\
\hline HL & 21.5 & KPS (1.6) & 108 & 45 & 2 & 21 & 5 \\
\hline GMA-HB & 4 & V59 (1.5) & 149 & 40 & 45 & 65 & 15 \\
\hline GMA-HL & 14.7 & $\begin{array}{c}\text { APS/ SMB } \\
(1.6)\end{array}$ & 144 & 45 & 0 & 48 & 8 \\
\hline
\end{tabular}

RDG: alkyd resin degree of grafting to the acrylic. RDB: fraction of reacted double bonds.

\subsection{Drier incorporation into latexes}

A water-emulsifiable, nonylphenolic ethoxylate-free drier (Additol VXW 6206, Cytec, Belgium) was used as a catalyst for the alkyd crosslinking reaction. The metal content of the drier, which includes 5 wt.\% Co, 0.22 wt.\% Li, and 7.5 wt.\% $\mathrm{Zr}$, is commonly used in alkyd formulations. ${ }^{29}$ The non-volatile matter is 65 wt.\% (measured after heating for $1 \mathrm{~h}$ at $125^{\circ} \mathrm{C}$ ). The dynamic viscosity is $150-1000 \mathrm{mPa} \cdot \mathrm{s}$ (measured with a shear rate of $25 \mathrm{~s}^{-1}$ at $23^{\circ} \mathrm{C}$ ). In some hybrid latex samples, the drier was added at either $1 \mathrm{wt} . \%$ or $2 \mathrm{wt} . \%$ (measured on the polymer weight) followed by stirring for 1 hr to achieve a uniform drier dispersion. Throughout this paper, hybrid latexes with 0 wt.\%, 1 wt. $\%$ and 2 wt.\% Additol drier will have a suffix of 0,1 and 2, respectively, on their code name.

\subsection{Nuclear Magnetic Resonance (NMR) Profiling}

The crosslinking process of the alkyd component in various alkyd/acrylic hybrid latex films was investigated using nuclear magnetic resonance (NMR) profiling. The experiments employed a permanent magnet, called GARField (Gradient At 
Right-angles to the Field) ${ }^{30,31,32}$ which was specifically designed to determine profiles of thin layers in the direction normal to the surface. Wet films $(c a .500 \mu \mathrm{m}$ thick, with a dried film thickness of $c a .200 \mu \mathrm{m})$ were cast onto clean glass coverslips $(2 \mathrm{~cm} \mathrm{x} 2$ $\mathrm{cm})$ and immediately placed in the magnet at a position corresponding to a magnetic field strength of $0.7 \mathrm{~T}$ and a field gradient strength of $17.5 \mathrm{Tm}^{-1}$. Signals were obtained using a quadrature echo sequence ${ }^{33}\left(90_{\mathrm{x}}-\tau-90_{\mathrm{y}}-\tau \text {-echo- } \tau \text { - }\right)_{n}$ for $n=32$ echoes and a pulse gap of $\tau=95 \mu \mathrm{s}$. To obtain a profile, the echoes were Fourier- transformed and then summed, thus giving an NMR signal intensity profile as a function of vertical position. The pixel resolution obtained with the parameters of these experiments is about $9 \mu \mathrm{m}$. To correct for the sensitivity decline over the film thickness, profile intensities were normalized by an elastomer standard. Films were dried under static air at a temperature of about $21^{\circ} \mathrm{C}$.

After the water has evaporated from the alkyd/acrylic hybrid latex films, the NMR signal is primarily attributed to the ${ }^{1} \mathrm{H}$ in the mobile alkyd phase. (Separate experiments on the acrylic copolymer latex showed that this phase does not have sufficient molecular mobility to provide a measurable signal.) The intensity of the ${ }^{1} \mathrm{H}$ NMR signal is proportional to the molecular mobility of any ${ }^{1} \mathrm{H}$-containing substance. Hence, a decrease of the signal is indicative of the crosslinking of the alkyd, because crosslinking restricts the molecular mobility of the polymer chains. ${ }^{2-6}$ GARField NMR profiling can provide information on how the crosslinking density varies with the vertical position in the film (i.e. distance from the substrate). Data were collected with an initial increment of $10 \mathrm{~min}$. for the first two hours, when most of the water is 
being lost. Then an increment of two hours was applied for the period up to $74 \mathrm{~h}$, during which the signal loss is attributed to the effects of crosslinking. The signals of some materials were recorded at regular intervals over a period of 60 days.

\subsection{Micro-indentation of alkyd-acrylic hybrid films}

Latex dispersions with 0 wt. $\%, 1$ wt.\% or 2 wt.\% drier were cast on cleaned glass substrates and allowed to dry in a still atmosphere at room temperature ( $\left.\mathrm{ca} .21^{\circ} \mathrm{C}\right)$. The dried latex films have a smooth surface and a thickness of $c a .350 \mu \mathrm{m}$. Micro-indentation experiments were performed on these films to evaluate their hardness as a function of time. A conical, stainless-steel indenter with its semi-angle at the apex of $\alpha=70.3^{\circ}$ was used. The tip of the indenter was polished to minimize its surface roughness. The area of contact of the indenter, $A$, is related to the depth of indentation, $h$, through the angle, $\alpha$, via the area-to-depth function: $A=\pi h^{2} \tan ^{2} \alpha=24.5 h^{2}$. This conical indenter has the same area-to-depth function as standard Berkovich and Vickers indenters. Hardness values were determined following the analysis presented in the literature. ${ }^{34,35,36}$

The indentation measurements employed a commercial instrument (Texture Analysizer, Stable Micro Systems Ltd., Godalming, UK), with an applied force held constant at $0.2 \mathrm{~N}$, and the loading and unloading speeds both set at $0.01 \mathrm{~mm} / \mathrm{sec}$. The applied force and the consequent indentation depth into the polymer film, however, both influence the measured film hardness. ${ }^{36}$ Figure S1 in the Supporting Information discusses the relation of hardness with differing indentation forces. An indentation 
force of $0.2 \mathrm{~N}$ was chosen as a result of this preliminary investigation. An effective hardness $\left(H_{\text {eff }}\right)$ will be reported here. The measurements are valid to use for comparisons between materials and for observing changes over time but do not provide absolute values.

Additional experiments were conducted to determine the fraction of molecules bonded within the film network. Films on glass substrates (prepared as for hardness measurements) were put into a reflux condenser containing tetrahydrofuran at a temperature of $70{ }^{\circ} \mathrm{C}$. After $48 \mathrm{~h}$ of solvent extraction, the weight fraction of the insoluble component was determined gravimetrically.

\subsection{Tensile deformation and modeling of tensile behaviors}

The alkyd/acrylic hybrid latex dispersions with 0 wt. $\%, 1$ wt. $\%$ and 2 wt. $\%$ drier were deposited in Teflon molds and allowed to dry for five days at room temperature. Then the films were lifted out of the molds and turned over to expose their underside to the atmosphere. They were allowed to crosslink for five additional days. Tensile specimens $(15 \mathrm{~mm} \times 4 \mathrm{~mm} \times 0.8 \mathrm{~mm})$ were cut from the dry films. Tensile stress-strain measurements were carried out with a commercial instrument (Stable Micro Systems Ltd., Godalming, UK) with a constant strain velocity of $5 \mathrm{~mm} \mathrm{~s}^{-1}$, corresponding to an initial strain rate of $c a .0 .33 \mathrm{~s}^{-1}$. The modeling method is described in a later section.

\section{Results and Discussion}




\subsection{Crosslinking rates in blends of alkyd and acrylic}

Alkyd is known to undergo auto-oxidation by reacting with atmospheric oxygen. However, this auto-oxidation process is very slow, and quite often metal catalysts are incorporated to facilitate the crosslinking process by speeding up the production of radicals in the system. The mechanisms of alkyd crosslinking with oxygen and the effect of the presence of metal catalysts are described elsewhere. ${ }^{2}$

GARField profiling studies of films cast from blends (i.e. admixtures) of alkyd-in-water emulsion and acrylic latex (50:50 weight ratio), for both the HB and HL resins without the presence of the metal catalyst drier indeed demonstrated a very slow crosslinking process up to 74 hours, as is shown in the Supporting Information as Fig. S2a and 2c. Here, the rate of crosslinking is judged by the rate at which the NMR signal decreases over time. The crosslinking of alkyd in the blend films is faster in the presence of the drier, as is shown in Fig. S2b and $2 d$.

In the presence of the drier, the alkyd crosslinking reactions in films cast from alkyd/acrylic blends are expected to increase the hardness. However, the phase separation between the alkyd and acrylic components and the accompanying non-uniform crosslinking results in wrinkled film surfaces (Supporting Information, Fig. S3), thereby preventing the blended alkyd/acrylic latex dispersions from being of any practical application. Their uneven surface also caused measurements of hardness to be unreliable and poorly reproducible.

\subsection{Crosslinking rates and hardness development in alkyd/acrylic hybrid films}




\subsubsection{Effect of drier concentration}

In the GARField results presented hereafter, the NMR intensities are plotted as a function of the vertical positions in the films. In all profiles, the film's air interface is represented on the right side of the profile, and the film/substrate interface is on the left side. The third axis shows time. The NMR intensity is proportional to the concentration of mobile ${ }^{1} \mathrm{H}$ in the drying films. This means that as the water evaporates and its concentration decreases, the signal intensity (vertical axis) and film thickness (horizontal axis) both decrease. After longer times, when all water has left the film, the remaining NMR signal is attributed to the molecular mobility of the alkyd component.

Figure 1 shows the NMR profiles of latex films cast from the hybrid latex with GMA functionalized hydrophobic alkyd (GMA-HB series) over times up to $74 \mathrm{~h}$ The data indicate that the films have virtually lost all of their water after $2 \mathrm{~h}$, because the film thickness at later times is stable. After this two-hour period, the film without added drier (referred to hereafter as GMA-HB0, with the final digit representing the drier wt.\% concentration) shows a very slow and gradual signal decrease. In comparison, films cast from the same hybrid latex with $1 \mathrm{wt} \%$ drier (referred to hereafter as GMA-HB1) shows a more obvious, faster signal decrease. The signal decrease is most significant in the latex film cast from the same hybrid latex but with 2 wt.\% drier (referred to hereafter as GMA-HB2). The loss of the signal is explained by the restricted molecular mobility in the crosslinked alkyd. The reaction of the alkyd with GMA has not prevented it from undergoing a crosslinking reaction, as is 
expected from its relatively low RDB value in Table 1 . The addition of the drier speeds up the crosslinking of alkyd, as expected.

Figure 1d presents a 2D profile of Figure 1c. The profiles reveal a strong non-uniformity with depth, particularly evident at times between 12 and $24 \mathrm{~h}$ (In any experiment, small errors in the leveling of the sample in relation to the magnetic field gradient direction reduce the resolution. Hence, there are a few pixels associated with the sharp interface between the coating and the substrate (at the left side of the profile). The non-uniform depth profile indicates greater crosslinking at the film surface in comparison to near the substrate. Such effects have been observed previously in neat alkyd films, cast from solvent ${ }^{3,6}$ and from emulsions ${ }^{2}$, but have never been reported for alkyd hybrids. The effect has been explained in the literature in the case of neat alkyds. A model has been proposed to correlate the concentration profile of oxygen when diffusing from the air interface with the position-dependence of the auto-oxidation reaction. ${ }^{3,6}$ 

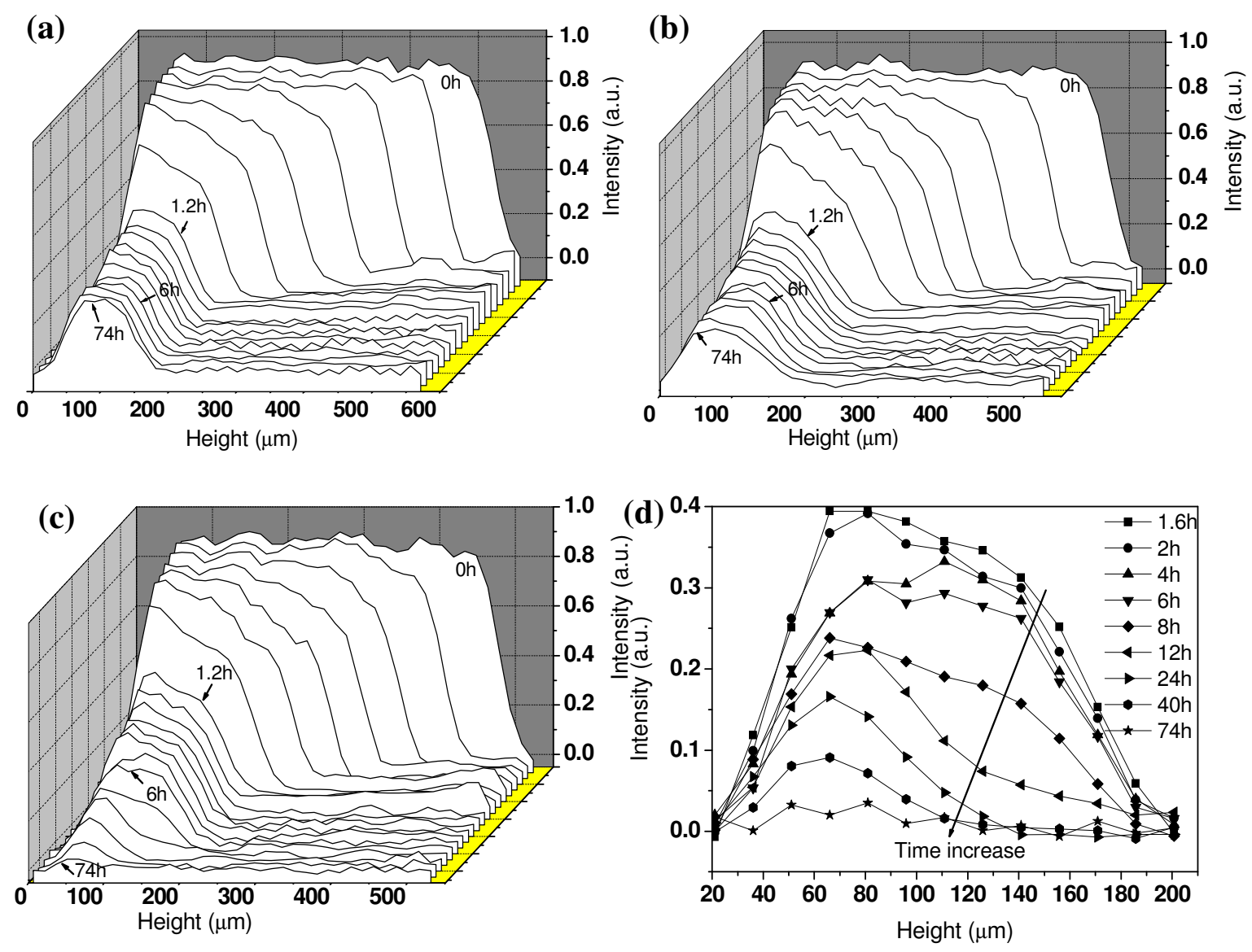

Figure 1. GARField profiles obtained over time up to 74 hours during the water loss and crosslinking of alkyd/acrylic hybrid films: (a) GMA-HB0; (b) GMA-HB1; and (c) GMA-HB2. Non-uniform profiles are particularly evident at times beyond 24 hours in GMA-HB2. At 74 hours, all signal has been lost. (d) 2-D profiles of GMA-HB2 for the times indicated in the legend.

The calculated total signal intensity of the profile (obtained by finding the area under the profile using the zeroth moment of statistics ${ }^{37}$ ) is proportional to the total concentration of mobile ${ }^{1} \mathrm{H}$ in the alkyd phase, and can thereby provide information on the drying kinetics with good sensitivity over long periods of time. The evolution of the signal intensities over time for hybrid GMA-HB0, GMA-HB1 and GMA-HB2 
is presented in Figure 2, in order to compare qualitatively the rates of alkyd crosslinking in the hybrid films. The intensity is normalized by dividing by the initial film thickness. The purpose of the normalization is to take into account small differences between the samples in their initial film thickness. Note that when the molecular mobility is sufficiently restricted, the NMR signal is lost. Yet the crosslinking reaction can continue to take place, of course, but it is beyond the sensitivity of the technique.

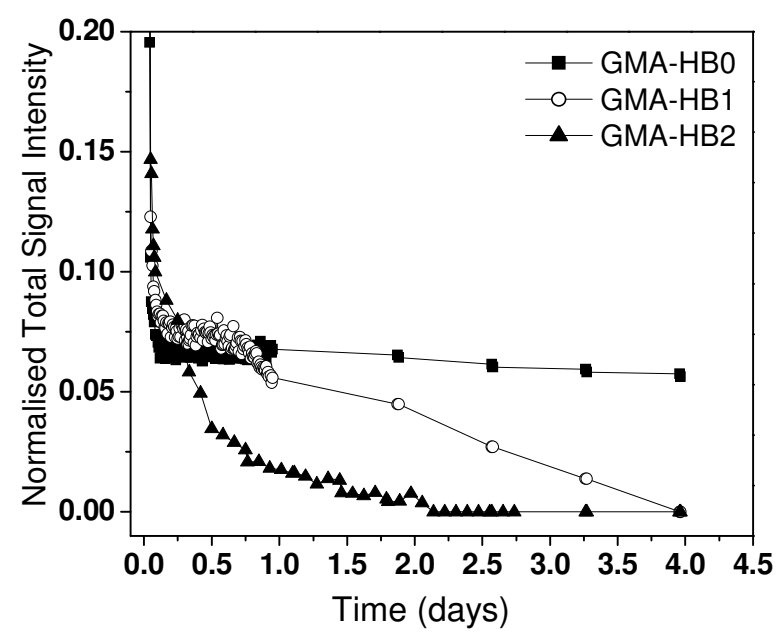

Figure 2. Total NMR signal intensity development over time for films of GMA-HB0, GMA-HB1 and GMA-HB2.

Figure 2 shows very different trends for the three hybrid films, and there is an obvious effect of the concentration of the drier. The rate of decrease of the total signal intensity for all three films is seen to decrease significantly after a time of about $2 \mathrm{~h}$, indicating that water loss is nearly complete. Any drop of the signal after $2 \mathrm{~h}$ for these hybrid latex films can be attributed to the effects of crosslinking. A normalized NMR signal intensity of 0.06 is observed after four days from the alkyd hybrid without drier (GMA-HB0). With 1 wt.\% drier (GMA-HB1), there is a steady decrease in the 
normalized signal intensity over time, and it approaches 0 after four days, indicating a slow but steady crosslinking reaction. Interestingly, the signal for the GMA-HB2, drops at a much greater rate and approaches 0 after two days. The film has hardened to an extent that signals are not detectable using the current parameters in the NMR experiment. Clearly, the presence of $2 \mathrm{wt} . \%$ drier is more effective in this hybrid compared to $1 \mathrm{wt} \%$. A concentration dependence is observed here, with a faster crosslinking being achieved with a greater concentration of the drier.

The micro-indentation values in Figure 3 show a hardness increase in the same hybrid latex films as crosslinking takes place. The micro-indentation experiments were conducted on films with a dried thickness of $c a .350 \mu \mathrm{m}$, compared with a dried film thickness $c a$. $200 \mu \mathrm{m}$ for NMR profiling. Hence, some small differences are anticipated in the extent of crosslinking in the two sets of films, because of the depth-dependence of the crosslinking reaction. As thicker films take a longer time to lose water and to crosslink uniformly, the time scales between NMR profiling and indentation are not directly comparable. Regardless of this, micro-indentation experiments demonstrate an effect of drier content on hardness development that is consistent with the trend seen in the NMR profiling experiments.

Figure 3a compares the indentation curves of GMA-HB0 after five days and ten days. The steepness of the curves is proportional to the hardness. A harder material will have a more shallow indentation compared to a softer material under the same load. NMR data in Figures $1 \mathrm{a}$ and 2 showed that GMA-HB0 can undergo a self-crosslinking process, but this process is very slow. The calculated $H_{\text {eff }}$ from 
Figure $3 \mathrm{a}$ is summarized in Table 2. $H_{\text {eff }}$ increases from $0.18 \mathrm{MPa}$ to $0.45 \mathrm{MPa}$, and this increase can be explained by an increase in the crosslink density.

The effect of drier concentration on indentation depth is shown in Figure $3 b$. After five days of drying, $H_{\text {eff }}$ is higher for GMA-HB1 and is four times higher for GMA-HB2 compared with GMA-HB0. Crosslinking is faster in the presence of more drier (as indicated in Figure 2), and the hardness is found to increase as more drier is added.
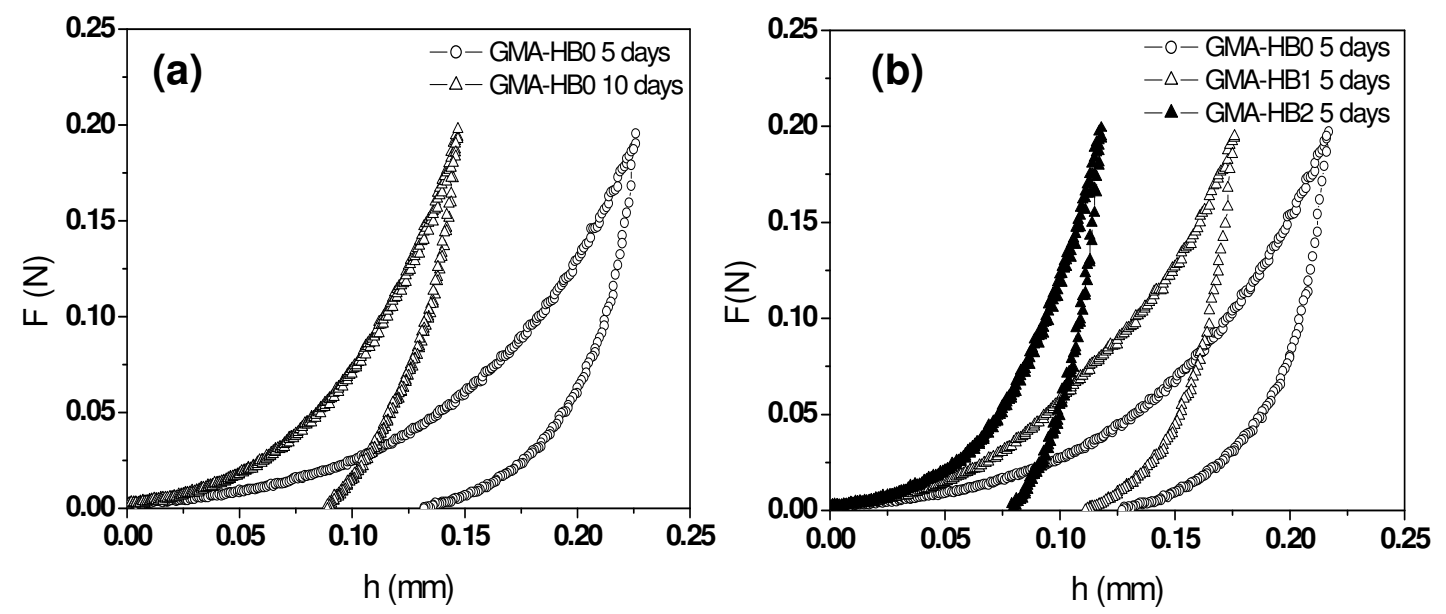

Figure 3. Indentation curves on hybrid latex films (dried film thickness ca. $350 \mu \mathrm{m}$ ) after film formation at room temperature: (a) GMA-HB0 after 5 or 10 days; (b) GMA-HB0, GMA-HB1 and GMA-HB2 for 5 days.

Table 2. Hardness values calculated from the indentation profiles in Figure 3

\begin{tabular}{|c|c|c|c|}
\hline Hybrid name & $\begin{array}{c}\text { Drier content } \\
\text { (wt. \%) }\end{array}$ & $\begin{array}{c}\text { Age } \\
\text { (days) }\end{array}$ & $H_{\text {eff }}(\mathrm{MPa})$ \\
\hline GMA-HB0 & 0 & 5 & $0.18 \pm 0.01$ \\
\hline GMA-HB0 & 0 & 10 & $0.45 \pm 0.06$ \\
\hline GMA-HB1 & 1 & 5 & $0.26 \pm 0.03$ \\
\hline GMA-HB2 & 2 & 5 & $0.73 \pm 0.05$ \\
\hline
\end{tabular}

\subsubsection{Effect of Alkyd Type and GMA Functionalization}


Subsequent experiments used a drier concentration fixed at $2 \mathrm{wt} . \%$ and explored the effects of the type of alkyd (HB or HL) and its functionalization with GMA. A comparison of the total signal intensity as a function of time for hybrid latex films with either functionalized or non-functionalized alkyd (both HB and HL) is shown in Figure 4. The plots show that functionalization with GMA has a large effect. The total signal intensity for hybrids with a functionalized alkyd (GMA-HB2 and GMA-HL2) both fall to 0 after two or three days. This loss of signal indicates that the mobility of the molecules has been highly restricted. In contrast, the total signal intensity of the HB2 hybrid reaches 0 only after 22 days, and that of the HL2 hybrid falls to 0.09 after 22 days. These results reveal that hybrids containing GMA-functionalized alkyds achieve a "hardened state" faster than the standard hybrids. Also, the rate of NMR signal loss is greater in the hydrophobic alkyd in comparison to the hydrophilic alkyd.
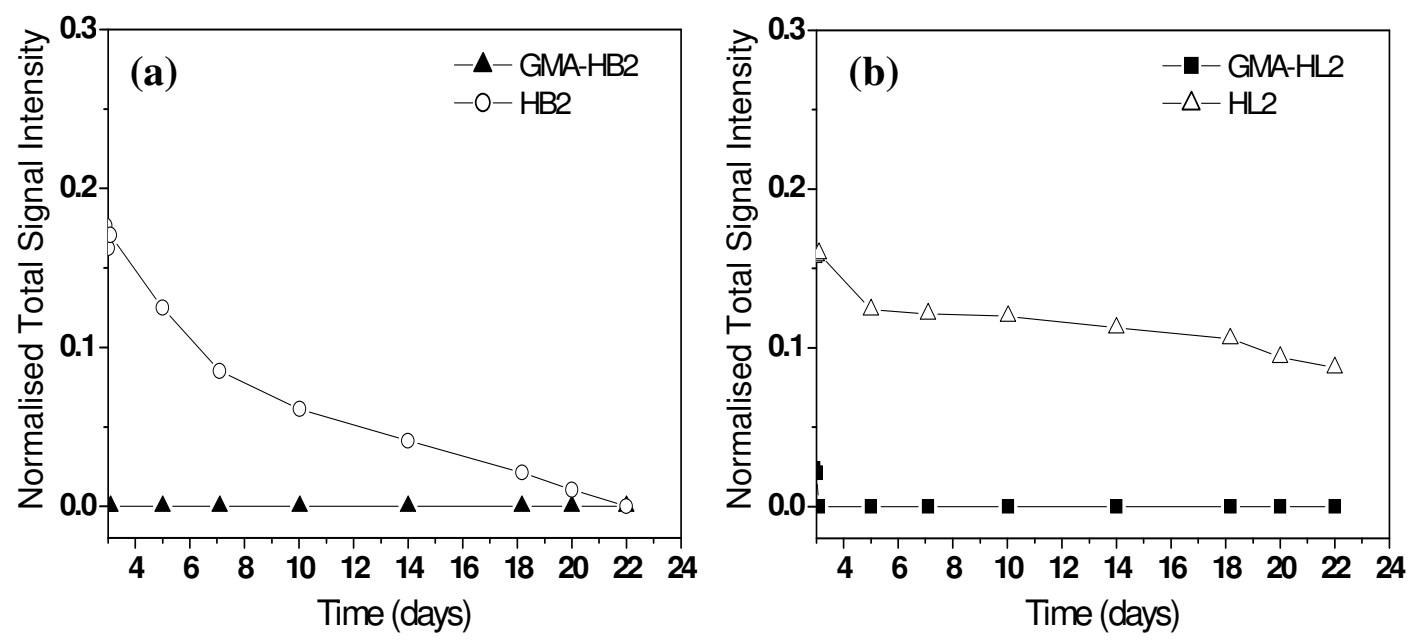

Figure 4. Total normalized NMR signal intensity developments up to 22 days for various types of alkyd/acrylic hybrid with 2 wt.\% drier: (a) HB2 and GMA-HB2, and (b) HL2 and GMA-HL2.

Figure 5 presents the micro-indentation curves of alkyd/acrylic hybrid latex films 
(containing 2 wt.\% drier and ca. $350 \mu \mathrm{m}$ thick), both with and without GMA-functionalization, after 10 days. It is apparent that the GMA-functionalized hybrid latex films have a lower indentation depth. The calculated $H_{\text {eff }}$ values summarized in Table 3 show that, regardless of whether the alkyd is hydrophobic or hydrophilic, the hybrid latex films have superior hardness values when the alkyd is functionalized with GMA. This effect is consistent with the conclusions drawn from Figure 4.
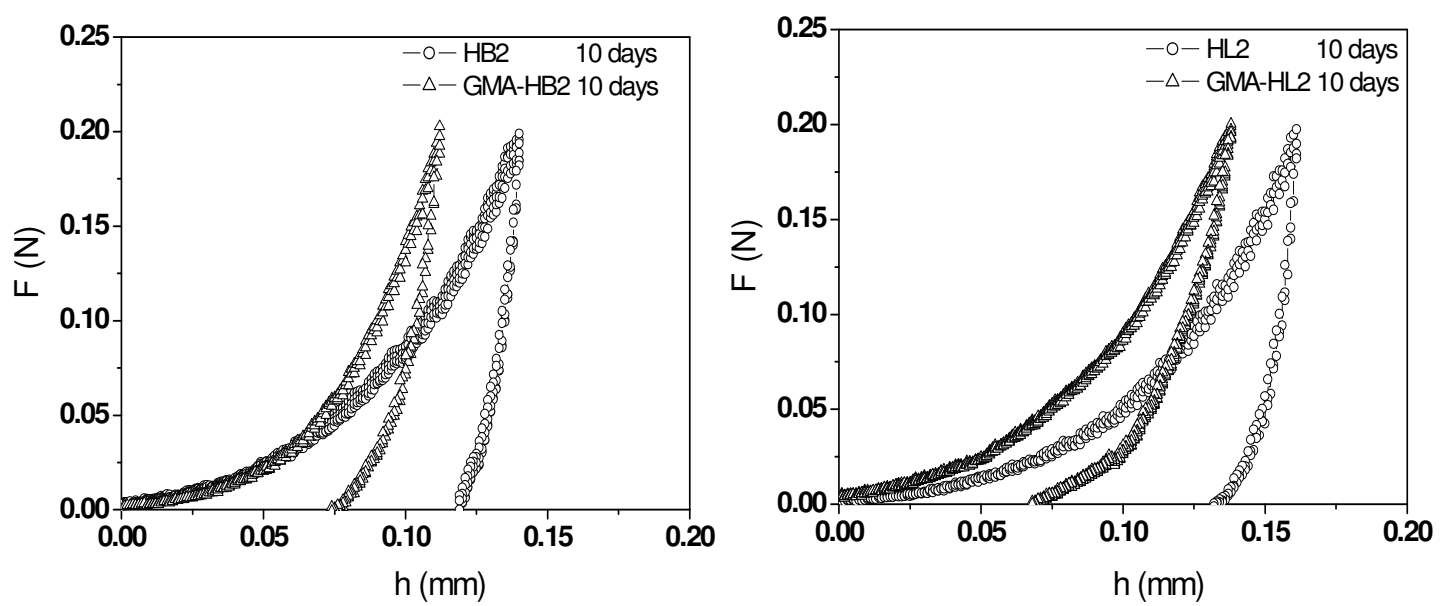

Figure 5. Indentation curves of HB2, GMA-HB2, HL2 and GMA-HL2 dried at room temperature for 10 days, as indicated in the legend.

Table 3. Hardness values calculated from the indentation curves presented in Figure 5 for hybrids with and without GMA functionalization

\begin{tabular}{|c|c|c|c|}
\hline Hybrid name & $\begin{array}{c}\text { Age } \\
\text { (days) }\end{array}$ & $H_{\text {eff }}(\mathrm{MPa})$ & $\begin{array}{c}\text { Insoluble } \\
\text { component } \\
\text { (wt. \%) }\end{array}$ \\
\hline GMA-HB2 & 10 & $0.80 \pm 0.03$ & $90 \pm 2.0$ \\
\hline HB2 & 10 & $0.42 \pm 0.02$ & $48 \pm 2.3$ \\
\hline GMA-HL2 & 10 & $0.57 \pm 0.04$ & $90 \pm 1.6$ \\
\hline HL2 & 10 & $0.34 \pm 0.03$ & $53 \pm 1.7$ \\
\hline
\end{tabular}


The NMR profiling results showed that, because of the auto-oxidative reactions of the unsaturated bonds along the alkyd backbone, the mobility of the alkyd chains decreased at a faster rate and to lower levels in the films cast from latexes synthesized with GMA-functionalized alkyd resins. In addition, in the micro-indentation experiments, these films showed a faster development of hardness, achieving higher values in a given time. These results indicate that more densely crosslinked networks were formed at a faster rate in films cast from latexes synthesized with GMA-functionalized alkyd resins. Note, however, that this result does not mean that the chemical reaction is faster for the GMA-functionalized alkyds. On the contrary, the mobile ungrafted alkyd resin is expected to be more reactive.

The reason for the faster formation of dense networks is that the GMA-functionalized resin was easily grafted to the acrylic chains through the methacrylate group. Table 1 shows that the RDG for the HB alkyd resin increases from $39 \%$ to $65 \%$ when it is functionalized with GMA. As the acrylic chains are much longer than the alkyd chains, the grafted alkyd becomes part of a much longer macromolecule, which is likely to contain several alkyd chains. Scheme1 compares the molecular structure of GMA-functionalized and non-functionalized alkyd/acrylic hybrids.

Auto-oxidation reactions of grafted alkyd moieties allow the formation of chemical bonds between the hybrid macromolecules, which lead to the faster formation of more densely crosslinked networks compared to the formation of a network among short, non-grafted alkyd chains. The lower extent of grafting of the 
hydrophilic (HL) alkyd resin (48\% as compared to the hydrophobic (HB) resin with a value of $65 \%$ (Table 1)) is, in fact, the likely reason for its relatively slower observed crosslinking rate. Furthermore, we note from the gel content measurements in 10-day old films containing 2 wt.\% drier that GMA functionalization of the alkyd results in 90 wt.\% of all molecules being part of the crosslinked network and hence insoluble (Table 3). Without this GMA functionalization, approximately 50 wt.\% of the molecules are soluble and not part of a larger crosslinked network. Scheme 1 shows schematically the reaction of grafted alkyd chains to create a network in the hybrid molecules. By comparison, non-functionalized alkyd chains can create a network of alkyd that is not attached to the acrylic molecules.
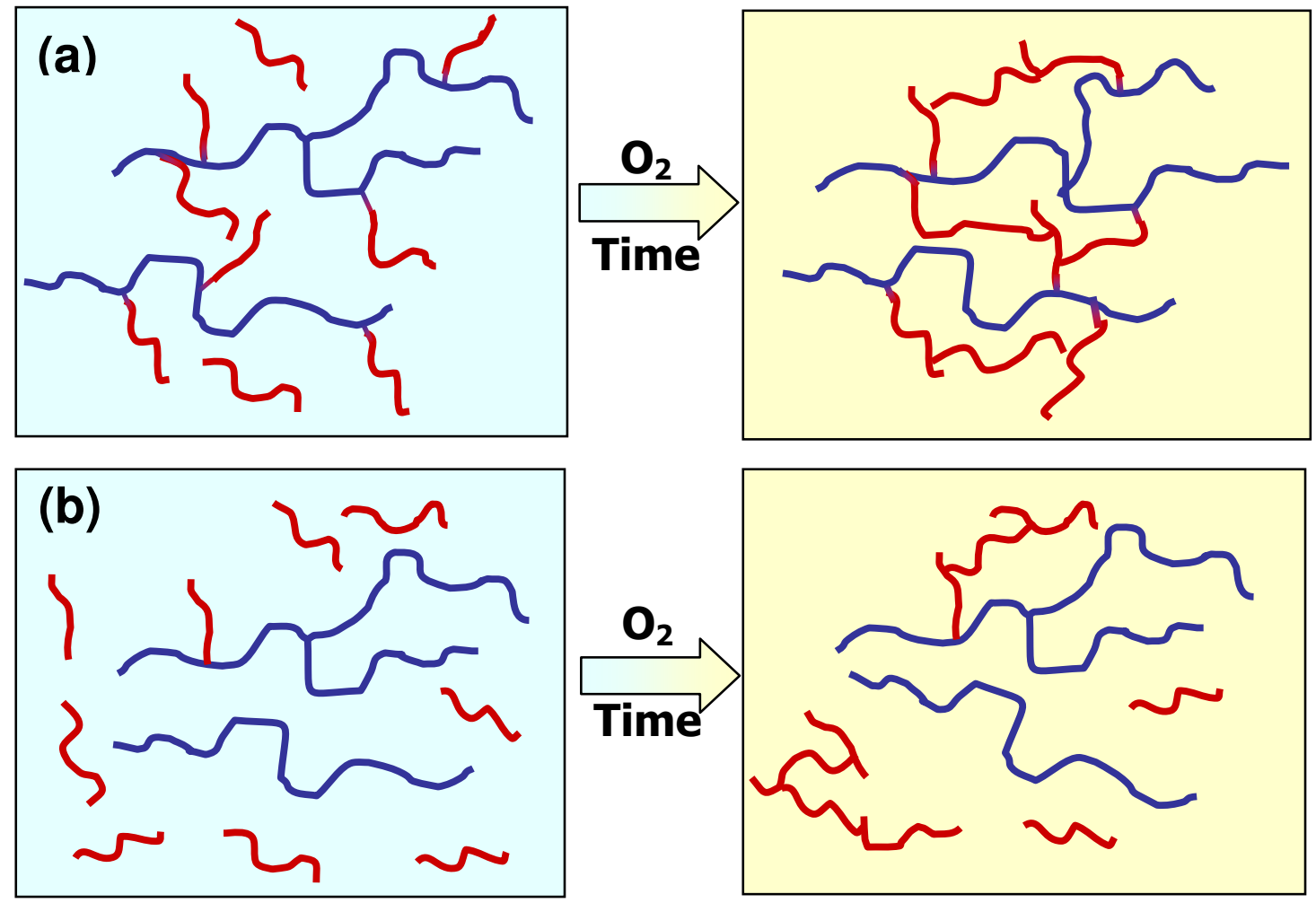

Scheme 1. Molecular structure of (a) GMA-functionalized and (b) non-functionalized alkyd/acrylic hybrid, before and after the alkyd's auto-oxidative crosslinking reaction. 
Acrylic molecules are shown in blue, and the pre-formed alkyd molecules are red.

\subsection{Depth-dependence of crosslinking in alkyd/acrylic hybrid films}

In addition to the faster crosslinking found when the alkyds are functionalized with GMA, an additional effect is that the crosslinking is more uniform with depth into the film. Figure 6 presents a comparison of the GARField profiles for all four types of hybrid with 2 wt.\% drier after drying for 18 days. The hybrid containing hydrophilic alkyd resin (HL2) presents the strongest signal out of the four materials, indicating that it has the lowest crosslinking density. The strong skewness in the profile reveals a decrease in the crosslinking density with increasing distance from the film surface. The hybrid containing hydrophobic (HB2) has a greater crosslinking density, compared to HL2, but there is evidence for some non-uniformity with depth. Profiles from the hybrids containing functionalized alkyds (GMA-HB2 and GMA-HL2) have no signal, indicating a high crosslinking density.

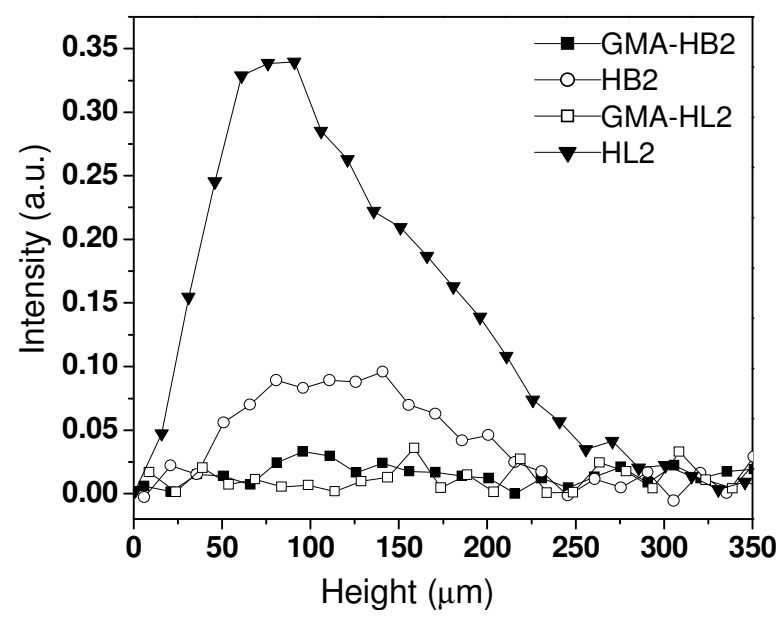

Figure 6. GARField profiles of hybrids (with 2 wt. $\%$ drier) obtained after 18 days for GMA-HB2; HB2; GMA-HL2; and HL2. 


\subsection{Large-strain deformation of alkyd-acrylic hybrid latex films and modelling}

Network formation affects the large-scale deformation behaviour of polymers, and so experiments were carried out to gain further insight into the crosslinked network in the hybrid films. A more tightly-crosslinked network will exhibit a higher elastic modulus at small strains and a greater amount of strain-hardening at large strains.

\subsubsection{Model for large-strain deformation}

The Gent model has been employed previously to predict large deformation behaviour of unentangled, crosslinked rubbery networks ${ }^{26}$ and hydrogels ${ }^{38,39}$ that undergo strain hardening at large strains. The Upper Convected Maxwell (UCM) model is used to predict the strain-softening behaviour of a viscoelastic polymer fluid. ${ }^{25}$ Recently, the combination of the Gent model with the UCM model has been employed to predict the large-scale deformation behaviour of soft polymers with a percolating crosslinked network. ${ }^{40,41}$ The viscoelastic component of the material is described by the UCM model, and the crosslinked, elastic component is described by the Gent model. A prediction of the uniaxial stress-strain curve is the sum of contributions to the stress from the UCM element and the Gent element, which can be written as:

$$
\sigma_{\mathrm{N}}(\lambda)=\sigma_{\mathrm{N}, \mathrm{v}}(\lambda)+\sigma_{\mathrm{N}, \mathrm{e}}(\lambda)
$$

where

$$
\sigma_{N, v}(\lambda)=\left(\frac{2 G_{v} D_{e}}{1-2 D_{e}}\left(1-\exp \left(-\frac{\left(1-2 D_{e}\right)}{D_{e}}(\lambda-1)\right)\right)+\frac{G_{v} D_{e}}{1+D_{e}}\left(1-\exp \left(-\frac{\left(1+D_{e}\right)}{D_{e}}(\lambda-1)\right)\right)\right) \cdot \lambda^{-1}
$$

and 


$$
\sigma_{\mathrm{N}, \mathrm{e}}(\lambda)=\left(\frac{\mathrm{G}_{\mathrm{e}}}{1-\frac{\lambda^{2}+2 / \lambda-3}{\mathrm{~J}}}\left(\lambda^{2}-1 / \lambda\right)\right) \cdot \lambda^{-1}
$$

where $G_{v}$ is the initial shear modulus of the viscoelastic part, $D_{e}$ is the Deborah number (the product of the relaxation time of the viscous component and the strain rate), $G_{e}$ is the small-strain shear modulus of the elastic part, $J_{\mathrm{m}}$ is the maximum experimental finite extensibility, and $\lambda$ is the extension ratio. $J_{\mathrm{m}}$ gives an indication of the density of the crosslinked network, and hence is highly useful in characterising a material. It takes on a lower value as the segments in the network become shorter after crosslinking, thus resulting in less extensibility. At high strains, the stress level rises sharply as the segments approach the limit of their extension.

A material must have a sufficiently viscoelastic component in order for this model to be applied. The model does not apply to materials that undergo yielding under applied strain, and therefore the mechanical properties of the hybrids must be considered prior to applying the model. Crosslinking is known to shift the glass transition temperature $\left(T_{g}\right)$ of a polymer towards a higher value. A single $T_{g}$ value in this series of hybrid latexes, as determined from DSC, is ca. $-20{ }^{\circ} \mathrm{C}$ before crosslinking. (See Fig. S4 in the Supporting Information. Two transitions are not observed, which indicates there is mixing at the molecular level. The low value of $T_{\mathrm{g}}$ indicates that the alkyd component is making a strong contribution.) After crosslinking of the hybrid occurs over a period of two months, there is an increase of the $T_{\mathrm{g}}$ to $c a .-10{ }^{\circ} \mathrm{C}$. Regardless of this shift, the $T_{g}$ value is far below room 
temperature, and the hybrid material is in a viscoelastic state at room temperature. The $T_{g}$ value in the same crosslinked hybrid, when determined by DMA, is $14{ }^{\circ} \mathrm{C}$ (Figure S5 in the Supporting Information).

The fact that the hybrids are in their rubbery states at room temperature ensures that the large-strain deformation behaviour is mainly viscoelastic rather than plastic. A tensile cycling test was conducted to confirm that the deformation is recoverable, as would be expected for viscoelastic deformation. Figure S6 in the Supporting Information reveals there is viscoelastic energy dissipation (proportional to the area of the hysteresis in the curves) and recovery of the deformation in crosslinked hybrids.

From all of these experiments, it is concluded that the alkyd/acrylic latex films can be considered to be in a viscoelastic state at room temperature. Some of the hybrids are particularly "soft" when crosslinking is not operative. The UCM model is therefore expected to describe the mechanical behaviour of the un-crosslinked component adequately, and the Gent model will adequately describe the mechanical behaviour of the crosslinked component as it develops.

\subsubsection{Experimental large-strain deformation results and modelling}

Figure 7 shows the effect of different amounts of drier on the large-strain deformation properties of the films cast from the GMA-HB hybrids. Both experimental and best fit data curves are shown. The fitted data are the sum of the stress from the viscoelastic component $\left(\sigma_{\mathrm{v}}\right)$ and elastic components $\left(\sigma_{\mathrm{e}}\right)$. It is demonstrated here that this combined model can well describe the non-linear 
large-strain deformation properties of alkyd/acrylic hybrid films. Near the last stage of the tensile deformation, as the material begins to fail, there is some plastic deformation. The model assumes elastic and viscoelastic deformation without considering the material failure, and hence it cannot predict the plastic deformation behaviour at the very high strains. Nevertheless, the very good fit with the data shows it describes the deformation up until the point of failure.
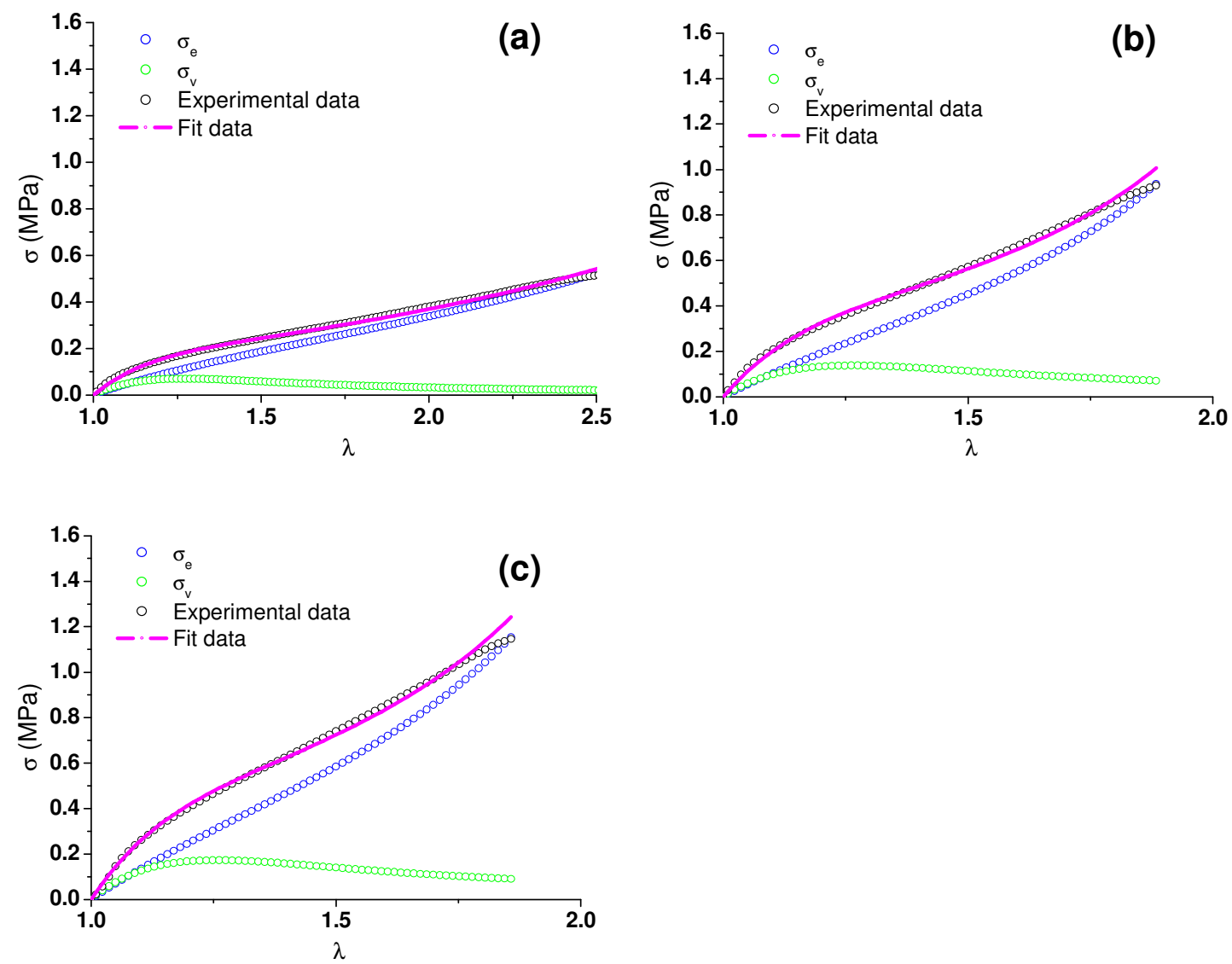

Figure 7. Experimental data and best-fit models of large-strain deformation behaviour of alkyd/acrylic hybrid films: (a) GMA-HB0, (b) GMA-HB1 and (c) GMA-HB2 after a drying period of 12 days. The fit data is the sum of the elastic and viscoelastic components, which are both shown for completeness. 
Table 4. Fitting parameters of various curves in Figure 7 showing the effects of drier concentration

\begin{tabular}{|c|c|c|c|c|c|c|c|c|}
\hline Hybrid name & $\begin{array}{c}\text { Drier } \\
\text { content } \\
(\mathrm{wt} \%)\end{array}$ & $\begin{array}{c}\text { Age } \\
(\text { day })\end{array}$ & $J_{\mathrm{m}}$ & $\begin{array}{c}\tau \\
(\mathrm{s})\end{array}$ & $\begin{array}{c}G_{\mathrm{v}} \\
(\mathrm{MPa})\end{array}$ & $\begin{array}{c}G_{\mathrm{e}} \\
(\mathrm{MPa})\end{array}$ & $G_{\mathrm{v}} / G_{\mathrm{e}}$ & $\begin{array}{c}E= \\
3\left(G_{\mathrm{e}}+G_{\mathrm{v}}\right) \\
(\mathrm{MPa})\end{array}$ \\
\hline GMA-HB0 & 0 & 12 & 17 & 0.50 & 0.23 & 0.17 & 1.35 & 1.20 \\
\hline GMA-HB1 & 1 & 12 & 4.4 & 0.48 & 0.47 & 0.37 & 1.27 & 2.52 \\
\hline GMA-HB2 & 2 & 12 & 4.4 & 0.46 & 0.61 & 0.48 & 1.27 & 3.27 \\
\hline
\end{tabular}

The curves in Figure 7 show a stiffening of the hybrids with the addition of the drier. The best-fit parameters are summarized in Table 4. The fitting illustrates that the $J_{\mathrm{m}}$ value, which indicates the maximal finite extensibility, is 17 for GMA-HB0 after 12 days of drying. In the presence of $1 \mathrm{wt} \%$ drier and when dried under the same conditions, GMA-HB1 has a $J_{\mathrm{m}}$ value of 4.4. Although $J_{\mathrm{m}}$ does not decrease further when the drier content is increased to $2 \mathrm{wt} . \%$, the fitting shows that the initial viscoelastic $\left(G_{\mathrm{v}}\right)$ and elastic $\left(G_{\mathrm{e}}\right)$ components of the shear modulus increase further. With further crosslinking, both $D_{\mathrm{e}}$ and the ratio of $G_{\mathrm{v}} / G_{\mathrm{e}}$ decrease, and $3\left(G_{\mathrm{v}}+G_{\mathrm{e}}\right)$ (which is the elastic modulus, $E$, of the materials) increases. All of these results can be explained by a greater density of crosslinking with a higher drier content.

Figure 8 demonstrates the effects of drying time on the large-strain deformation behavior of GMA-HB0 and GMA-HB1. For both materials, crosslinking is found to continue up to 60 days. Modelling of these large-strain curves finds that $J_{m}$ decreases to 3.8 for both of them, and the elastic modulus of GMA-HB0 and GMA-HB1 reaches 
3.8 and 4.6 MPa, respectively, after 60 days. The full analysis is presented in Table 5. The effect of the drier in increasing the rate of network formation, and hence the modulus after 60 days, is apparent.
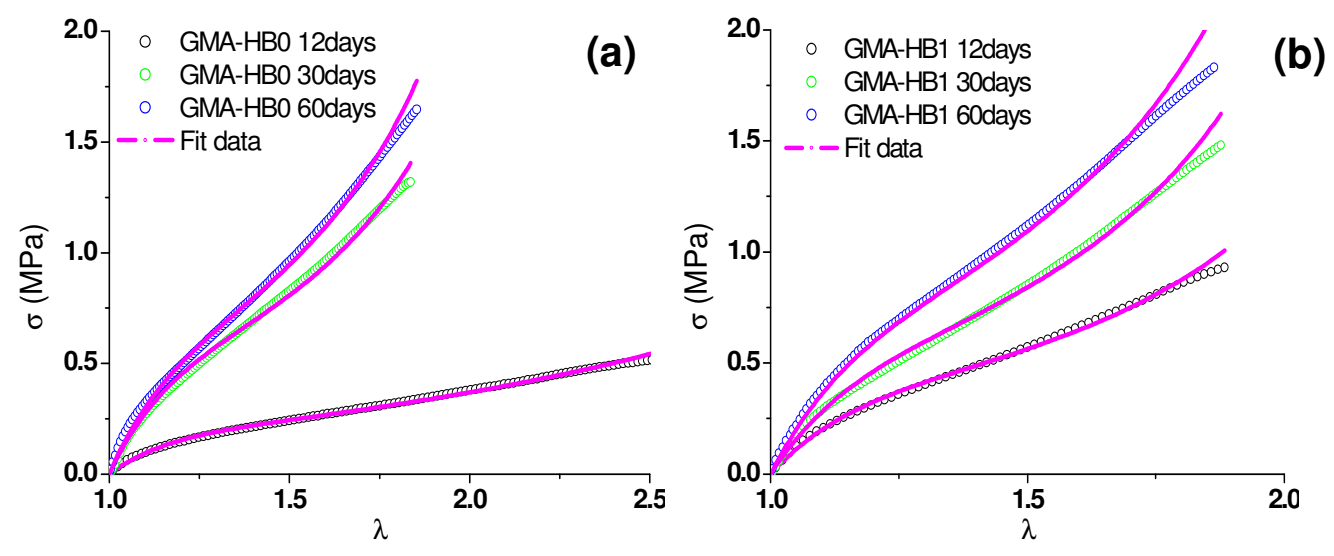

Figure 8. Experimental large-strain deformation data and modelling of (a) GMA-HB0 and (b) GMA-HB1 dried after 12, 30 and 60 days.

Table 5. Fitting parameters of curves in Figure 8 showing the effects of film age and drier content

\begin{tabular}{|c|c|c|c|c|c|c|c|c|}
\hline $\begin{array}{c}\text { Hybrid } \\
\text { name }\end{array}$ & $\begin{array}{c}\text { Drier } \\
\text { content } \\
(\mathrm{wt} \%)\end{array}$ & $\begin{array}{c}\text { Age } \\
(\mathrm{day})\end{array}$ & $J_{\mathrm{m}}$ & $\begin{array}{c}\tau \\
(\mathrm{s})\end{array}$ & $\begin{array}{c}G_{\mathrm{v}} \\
(\mathrm{MPa})\end{array}$ & $\begin{array}{c}G_{\mathrm{e}} \\
(\mathrm{MPa})\end{array}$ & $G_{\mathrm{v}} / G_{\mathrm{e}}$ & $\begin{array}{c}E= \\
3\left(\mathrm{G}_{\mathrm{e}}+\mathrm{G}_{\mathrm{v}}\right) \\
(\mathrm{MPa})\end{array}$ \\
\hline GMA-HB0 & 0 & 12 & 17 & 0.50 & 0.23 & 0.17 & 1.35 & 1.20 \\
\hline GMA-HB0 & 0 & 30 & 3.9 & 0.48 & 0.62 & 0.53 & 1.17 & 3.45 \\
\hline GMA-HB0 & 0 & 60 & 3.8 & 0.45 & 0.65 & 0.60 & 1.08 & 3.75 \\
\hline GMA-HB1 & 1 & 12 & 4.4 & 0.48 & 0.47 & 0.37 & 1.27 & 2.52 \\
\hline GMA-HB1 & 1 & 30 & 3.8 & 0.46 & 0.62 & 0.56 & 1.11 & 3.54 \\
\hline GMA-HB1 & 1 & 60 & 3.8 & 0.44 & 0.78 & 0.74 & 1.05 & 4.56 \\
\hline
\end{tabular}


We next consider the hybrid films containing the non-functionalized hydrophobic alkyd (HB) in order to explore the effects of the functionalization. Figure 9 shows the experimental and best-fit data of hybrid films with 2 wt.\% drier (HB2) after 12 days. The stress-strain curve is identical to what was found when no drier is added (HB0); the latter is not presented in Figure 9 in the interests of visual clarity. The best-fit parameters used to model the experimental curves are identical for HB2 and HB0. Thus, in the long-range deformation, the drier has no effect. The value of $J_{m}$ of non-functionalized latex films with or without the presence of drier is infinite, which indicates that the HB resin has not been crosslinked sufficiently to create a continuous network. A large fraction of the alkyd chains are not grafted to the acrylic phase and so they do not contribute to hybrid network structure, which is probed in the large-strain deformation. See Scheme 1.

GARField NMR profiling is sensitive to lower levels of crosslinking that alter the alkyd molecular mobility, regardless of whether they are grafted to the acrylic component. Hence, that technique can detect an effect of the drier in all hybrids. The large-scale deformation is sensitive to the extended crosslinked network. The data show that this network is not modified in the case of HB2. Comparison of the data in Tables 4 and 6, and recalling the results for GMA-HB2 shown previously in Figure 7c, leads to the conclusion that GMA functionalization is essential in the hybrids for the creation of a continuous, crosslinked network. The hybrid is rather liquid-like and $J_{\mathrm{m}}$ is infinite when the HB alkyd resin is not functionalized, whereas it is more elastic with $J_{\mathrm{m}}=4.4$ in the corresponding GMA-functionalized hybrid. 
The differences in network properties of the GMA-HB films in comparison to the HB films can be better understood by considering the particle structures that have been reported elsewhere. ${ }^{18,22}$ In TEM images, the HB resin appears mainly in the core of the particles, whereas the GMA-functionalized HB resin was more homogeneously distributed throughout the particle. This closer mixing of the alkyd and acrylic phases was facilitated by the grafting reactions through the GMA moieties. The grafting contributes to the network development. In a 10 day-old film, only 48 wt. $\%$ of the molecules were attached to the network in a HB2 film, whereas $90 \mathrm{wt} . \%$ were grafted in the GMA-HB2 film.

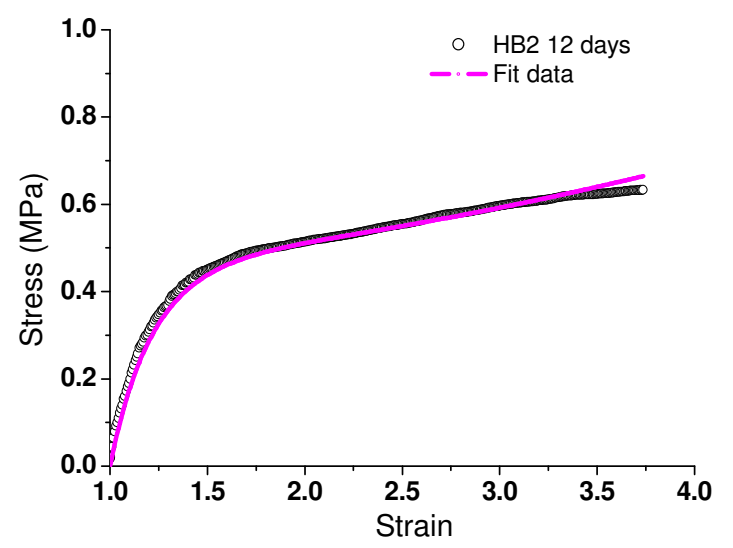

Figure 9. Experimental large-strain deformation data and modelling of HB2 alkyd/acrylic film after 12 days.

Table 6. Fitting parameters of HBO and HB2 films in Figure 9

\begin{tabular}{|c|c|c|c|c|c|c|c|c|}
\hline $\begin{array}{c}\text { Hybrid } \\
\text { name }\end{array}$ & $\begin{array}{c}\text { Drier } \\
\text { content } \\
(\mathrm{wt} \%)\end{array}$ & $\begin{array}{c}\text { Age } \\
(\text { day })\end{array}$ & $J_{\mathrm{m}}$ & $\begin{array}{c}\tau \\
(\mathrm{s})\end{array}$ & $\begin{array}{c}G_{\mathrm{v}} \\
(\mathrm{MPa})\end{array}$ & $\begin{array}{c}G_{\mathrm{e}} \\
(\mathrm{MPa})\end{array}$ & $G_{\mathrm{v}} / G_{\mathrm{e}}$ & $\begin{array}{c}E= \\
3\left(G_{\mathrm{e}}+G_{\mathrm{v}}\right) \\
(\mathrm{MPa})\end{array}$ \\
\hline $\mathrm{HB} 0$ & 0 & 12 & $\infty$ & 1.3 & 0.45 & 0.18 & 2.5 & 1.89 \\
\hline
\end{tabular}




\begin{tabular}{|l|l|l|l|l|l|l|l|l|}
\hline HB2 & 2 & 12 & $\infty$ & 1.3 & 0.45 & 0.18 & 2.5 & 1.89 \\
\hline
\end{tabular}

$\infty$ : Defined when $J_{\mathrm{m}}>10^{6}$

Finally, we consider the deformation of the hybrids containing the hydrophilic alkyd. The comparison in Figure 10 further demonstrates the effect of GMA functionalization on the development of a crosslinked network. The $J_{m}$ of GMA-HL2 is 5.2 after drying for 12 days, whereas the $J_{m}$ of HL2 is infinite. With crosslinking in the functionalized alkyd hybrid, the modulus is more than three times higher than in the non-functionalized film.

The differences in the network formation are consistent with differences in the particle structures, reported elsewhere. ${ }^{22}$ The HL resin was found outside of the latex particles, where the GMA-HL resin was more homogeneously distributed, according to TEM analysis. Grafting between the acrylic and alkyd phases led to the homogeneity of the particles. In turn, the alkyd/acrylic grafting and compatibilizaton contributed to a denser network formation. In 10-day old films, 90 wt.\% of the molecules were incorporated into the network of the GMA-HL2 film, whereas only 53 wt.\% was contained in the HL2 film (Table 3). 


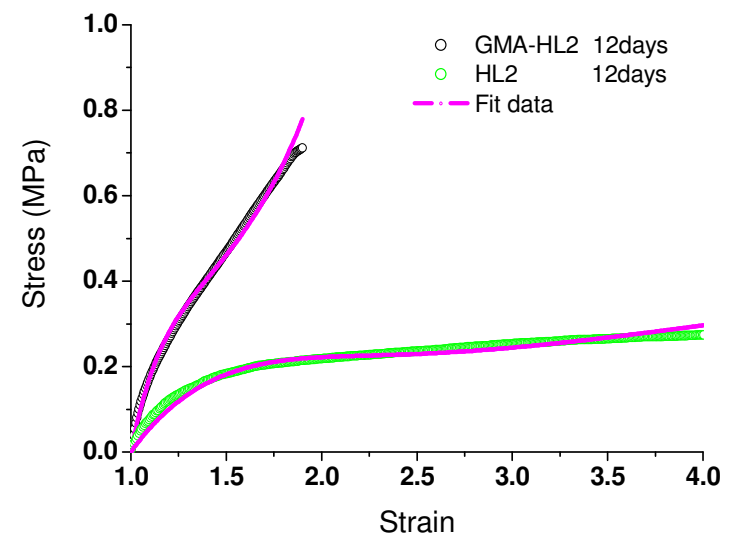

Figure 10. Experimental data and modelling of the large-strain deformation of GMA-HL2 and HL2 alkyd-acrylic films after 12 days.

Table 7. Fitting parameters of the curves in Figure 10

\begin{tabular}{|c|c|c|c|c|c|c|c|c|}
\hline Hybrid name & $\begin{array}{c}\text { Drier } \\
\text { content } \\
(\mathrm{wt} \%)\end{array}$ & $\begin{array}{c}\text { Age } \\
(\text { day })\end{array}$ & $J_{\mathrm{m}}$ & $\begin{array}{c}\tau \\
(\mathrm{s})\end{array}$ & $\begin{array}{c}G_{\mathrm{v}} \\
(\mathrm{MPa})\end{array}$ & $\begin{array}{c}G_{\mathrm{e}} \\
(\mathrm{MPa})\end{array}$ & $G_{\mathrm{v}} / G_{\mathrm{e}}$ & $\begin{array}{c}E= \\
3\left(G_{\mathrm{e}}+G_{\mathrm{v}}\right) \\
(\mathrm{MPa})\end{array}$ \\
\hline GMA-HL2 & 2 & 12 & 5.2 & 0.45 & 0.46 & 0.30 & 1.53 & 2.28 \\
\hline HL2 & 2 & 12 & $\infty$ & 1.9 & 0.14 & 0.07 & 2.00 & 0.63 \\
\hline
\end{tabular}

$\infty$ : Defined when $J_{\mathrm{m}}>10^{6}$

\section{Concluding Summary}

An alkyd/acrylic hybrid latex, prepared by miniemulsion polymerization, has been shown to form hard, crosslinked films at room temperature. The alkyd resin is able to undergo auto-oxidative crosslinking after its incorporation within the hybrid. The drier is effective in catalysing the alkyd crosslinking reaction. The rate of film hardening is faster, and a denser and more continuous network is formed, when the alkyd is functionalized with glycidyl methacrylate before its incorporation into the hybrid. The alkyd functionalization ensures a greater amount of grafting between the 
alkyd resin and the acrylic copolymer without consuming the unsaturated bonds of the alkyd backbone. Auto-oxidation of the alkyd moieties belonging to the large graft macromolecules led to the faster formation of more densely crosslinked networks, which can be contrasted to the formation of a network of free, short alkyd chains that are disconnected from the acrylic component.

Large-strain tensile deformation data showed that the greater crosslinking density achieved in the GMA-functionalized alkyd hybrid results in a high elastic modulus and a dense network with a low maximum extensibility. In contrast, there is a much less dense network with very high extensibility in the non-functionalized alkyd hybrids. A more hydrophilic alkyd resin achieves a lower amount of grafting in comparison to a more hydrophobic alkyd, and hence it shows a slower rate of hardening and a lower final hardness.

Whereas there have been several previous reports of the synthesis of alkyd/acrylic hybrid latex, this was the first thorough examination of the resulting mechanical properties. It was demonstrated that the GMA-functionalized hydrophobic alkyd/acrylic hybrid latex develops the tightest crosslinked network and the greatest hardness, making it the most promising of the materials for application as a protective coating.

Acknowledgements. Funding for this work was provided by the European Commission's Framework 6 Programme (NAPOLEON project, Contract No. 011844-2). Monika Goikoetxea is grateful for financial support from "Ayudas de Especialización de Investigadores Doctores de la UPV/EHU 2009”. We benefitted 
from useful discussions with Prof. Costantino Creton (Paris Tech - ESPCI). We thank André Utgenannt for assistance with materials preparation and data collection, Mrs. Violeta Doukova (University of Surrey) for general assistance in the laboratory, and Mr. Argyrios Georgiadis for assistance with the TOC image.

Supporting Information Available: The relation between $H_{e f f}$ and indentation forces. Magnetic resonance profiles of films cast from blends of acrylic latex and alkyd emulsions, with and without added drier. Photographs of blend and hybrid films made from HB and HL alkyd. DSC analysis of alkyd in crosslinked alkyd/acrylic hybrid latex films. DMA of acrylic in crosslinked alkyd/acrylic hybrid latex films. Tensile cycling of crosslinked alkyd/acrylic hybrid latex films. This information is available free of charge via the Internet at http://pubs.acs.org 
Published in Langmuir (2010) 26(17) pp. 14323-14333

Table of Contents only

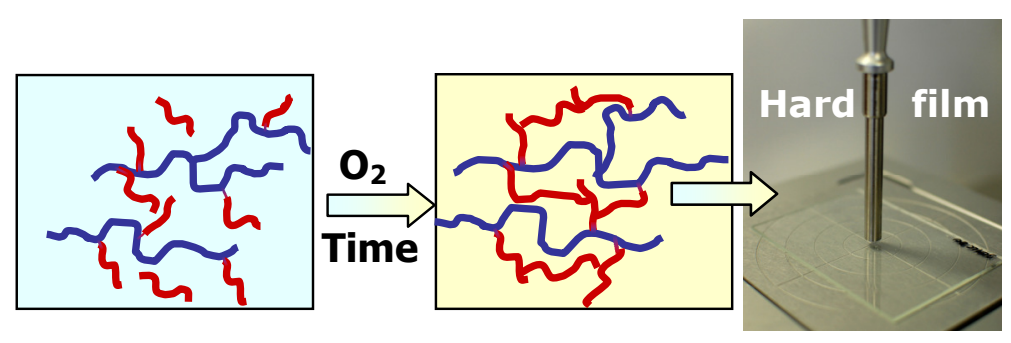




\section{References}

${ }^{1}$ Marton, B.; van der Ven, L. G. J.; Otto, C.; Uzunbajakava, N.; Hempenius, M. A.; Vancso, G. J. Polymer 2005, 46, 11330-11339.

${ }^{2}$ Mallégol, J.; Barry, A. M.; Ciampi, E.; Glover, P. M.; McDonald, P. J.; Keddie, J. L.; Wallin, M.; Motiejauskaite, A.; Weissenborn, P. K. J. Coat. Technol. 2002, 74, 113-124.

${ }^{3}$ Erich, S. J. F.; van der Ven, L. G. J.; Huinink, H. P.; Pel, L.; Kopinga, K. J. Phys. Chem. B 2006, 110, 8166-8170.

${ }^{4}$ Erich, S. J. F.; Laven, J.; Pel, L.; Huinink, H. P.; Kopinga, K. Polymer 2006, 47, 1141-1149.

${ }^{5}$ Erich, S. J. F.; Laven, J.; Pel, L.; Huinink, H. P.; Kopinga, K. Prog. Org. Coat. 2006, 55, 105-111.

${ }^{6}$ Erich, S. J. F.; Laven, J.; Pel, L.; Huinink, H. P.; Kopinga, K. Appl. Phys. Lett. 2005, 86, 134105.

${ }^{7}$ Overbeek, A.; Bückmann, F.; Martin, E.; Steenwinkel, P.; Annable T. Prog, Org, Coat. 2003, 48, 125-139.

${ }^{8}$ Keddie J.L. and Routh A.F. Fundamentals of Latex Film Formation: Processes and Properties. Springer: Berlin, 2010; Chapter 1.

${ }^{9}$ Overbeek, A. JCT Research 2010, 7, 1-21.

${ }^{10}$ Guyot, A.; Landfester, K.; Schork, F. J.; Wang, C. P. Prog. Polym. Sci. 2007, 32, 1439-1461.

11 Nabuurs, T. ; Baijards, R. A.; German, A. L. Prog. Org. Coat. 1996, 27, 163-172.

12 Guo, J.; Schork, F. J. Macromol. React. Eng. 2008, 2, 265-276.

${ }^{13}$ Wang, S. T.; Schork, F. J.; Poehlein, G. W.; Gooch, J. W. J. Appl. Polym. Sci. 1996, 60, 2069-2076. 
${ }^{14}$ Wu, X.; Schork, F.; Gooch, J. J. Polym. Sci. A Polym. Chem. 1999, 37, 4159-4168.

15 Colombini, D.; Jowkar-Deriss, M.; Karlsson, O J.; Maurer, F. H. J. Macromolecules 2004, 37, 2596-2602.

${ }^{16}$ Shoaf, G.L.; Stockl R.R. Polym. React. Eng., 2003, 11, 319-334.

17 Van Hamersveld, E.M.S.; Van Es, J.J.G.S.; German, A.L.; Cuperis, F.P.; Weissenborn, P.; Hellgren, A.-C. Prog. Org. Coat., 1999, 35, 235-246.

${ }^{18}$ Goikoetxea, M.; Minari, R. J.; Beristain, I.; Paulis, M.; Barandiaran, M. J.; Asua, J. M. J. Polym. Sci. A Polym. Chem. 2009, 47, 4871-4885.

${ }^{19}$ Minari, R.; Goikoetxea, M.; Beristain, I.; Paulis, M.; Barandiaran, M. J.; Asua, J. M. Polymer 2009, 50, 5892-5900.

20 Tsavalas, J.G.; Schork, F.J.; Landfester, K. JCT Res. 2004, 1, 53-63.

${ }^{21}$ Faucheu, J.; Chazeau, L.; Gauthier, C.; Cavaillé, J.-Y.; Goikoetxea, M.; Minari, R.; Asua, J.M. Langmuir, 2009, 25, 10251-10258.

${ }^{22}$ Goikoetxea, M.; Minari, R. J.; Beristain, I.; Paulis, M.; Barandiaran, M. J.; Asua, J. M., submitted for publication.

23 Wallin, M.; Glover, P. M.; Hellgren, A. C.; Keddie, J. L.; McDonald, P. J. Macromolecules 2000, 33, 8443-8452.

${ }^{24}$ Hellgren, A. C.; Wallin, M.; Weissenborn, P. K.; McDonald, P. J.; Glover, P. M.; Keddie, J. L. Prog. Org. Coat. 2001, 43, 85-98.

25 Bird, R. B.; Armstrong, R. C.; Hassager, O. Dynamics of Polymeric Liquids: Vol 1 Fluid Mechanics. $2^{\text {nd }}$ ed.; Wiley: New York, 1987.

${ }^{26}$ Gent, A. N. Rubber. Chem. Technol. 1996, 69, 59-61.

27 Minari, R. J.; Goikoetxea, M.; Beristain, I.; Paulis, M.; Barandiaran, M. J.; Asua, J. M. J. Appl. Polym. Sci. 2009, 114, 3143-3151. 
28 Official Methods of Analysis of AOAC International, AOAC International, Arlington, 1984, AOAC Official Method 28.023, Iodine Absorption Number Wijs Method.

29 Häggman, B.; Bjornberg, H.; Midelf, B.; James, D.B. World patent WO/2004/037928. Air drying waterborne resin composition. 2004.

${ }^{30}$ Glover, P. M.; Aptaker, P. S.; Bowler, J. R.; Ciampi, E.; McDonald, P. J. J. Magn. Reson. 1999, 139, 90-97.

${ }^{31}$ Gorce, J. P.; Bovey, D.; McDonald, P. J.; Palasz, P.; Taylor, D.; Keddie, J. L. Eur. Phys. J. 2002, 8, 421-429.

32 Bennet, G.; Gorce, J. P.; Keddie, J. L.; McDonald, P. J.; Berglind, H. Magn. Reson. Imaging 2003, 21, 235-241.

33 McDonald, P. J.; Newling, B. Rep. Prog. Phys. 1998, 61, 1441-1492.

${ }^{34}$ Oliver, W. C.; Pharr, G. M. J. Mater. Res. 1992, 7, 1564-1583.

${ }^{35}$ Xu, K. W.; Hou, G. L.; Hendrix, B. C.; He, J. W.; Sun, Y.; Zheng, S.; Bloyce, A.; Bell, T. J. Mater. Res. 1998, 13, 3519-3526.

36 Malzbender, J.; den Toonder, J. M. J.; Balkenende, A. R.; de With, G. Mater. Sci. Eng. R. 2002, 36, 47-103.

37 König, A. M.; Weerakkody, T. G.; Keddie, J. L.; Johannsmann, D. Langmuir 2008, $24,7580-7589$.

38 Webber, R. E.; Creton, C.; Brown, H. R.; Gong, J. P. Macromolecules 2007, 40, 2919-2927.

39 Miquelard-Garnier, G..; Hourdet, D.; Creton, C. Polymer 2009, 50, 481-490.

${ }^{40}$ Deplace, F.; Rabjohns, M. A.; Yamaguchi, T.; et al. Soft Matter 2009, 5, 1440-1447. 
${ }^{41}$ Deplace, F.; Carelli, C.; Langenfeld, A.; Rabjohns, M. A.; Foster, A. B.; Lovell, P. A.; Creton, C. ACS Appl. Mater. Interfaces 2009, 1, 2021-2029.

\section{Table of Contents}

See before References 